\title{
Enhanced reutilization value of shrimp-shell waste via fed-batch biodegradation with higher production of reducing sugar, antioxidant, and DNA protective compounds
}

\author{
Harun Ar Rashid', Hyun Yi Jung ${ }^{2}$ and Joong Kyun Kim ${ }^{1,2^{*}}$
}

\begin{abstract}
As a process for commercial application, production of reducing sugar, antioxidant, and DNA protective compounds from shrimp-shell powder was investigated in a fed-batch biodegradation using Bacillus cereus EW5. The fed-batch biodegradation was operated in a 5-L bioreactor for $96 \mathrm{~h}$ according to three times pulse-feeding strategy. On the basis of the equal working volume $(3 \mathrm{~L})$, the fed-batch biodegradation showed a better production of the target compounds than the batch biodegradation, with higher cell density and shortened biodegradation period. The maximum values of the target compounds were $0.297 \mathrm{mg} / \mathrm{mL}$ of reducing sugar, $92.35 \%$ DPPH radical scavenging activity, $98.16 \%$ ABTS radical scavenging activity, and 1.55 reducing power at $A_{700}$, which were approximately $12.1,3.4,5.2$, and $8.4 \%$ enhanced, respectively, compared with those obtained from the batch biodegradation. The fed-batch culture supernatant also showed the enhanced DNA damage inhibition activity than the batch culture supernatant. As a result, the fed-batch biodegradation accompanied by high cell density could produce more useful compounds, enabling an increase in the reutilization value of shrimp-shell waste.
\end{abstract}

Keywords: Shrimp-shell waste, Reducing sugar, Antioxidant activity, DNA protective ability, Fed-batch biodegradation

\section{Background}

Shrimp-shell waste (SSW) is generated in huge quantities from the shrimp processing industries throughout the world, and it is primarily disposed of into the sea, causing intense environmental pollution (Suresh 2012). Since this chitinous waste is considered as a valuable renewable resource, related studies have been carried out to convert it into useful compounds. Recently, environmentally friendly reutilization of SSW using microorganisms has attracted our interest. Thereupon, fermentation productions of chitin, mono-, di-, and oligo-saccharides have been reported from SSW

\footnotetext{
* Correspondence: junekim@pknu.ac.kr

${ }^{1}$ KOICA-PKNU International Graduate Program of Fisheries Science, Graduate

School of Global Fisheries, Pukyong National University, Busan 48513,

Republic of Korea

${ }^{2}$ Department of Biotechnology, Pukyong National University, Busan 48513,

Republic of Korea
}

by chitin-degrading bacterial strains (Halder et al. 2013; Sorokulova et al. 2009; Wang et al. 2012). The chitosaccharides have exhibited diverse functional properties, such as antitumor activity (Liang et al. 2007; Wang et al. 2008b), antimicrobial activity (Tsai et al. 2000; Wang et al. 2008a; Wang and Yeh 2008), and antioxidant activity (Annamalai et al. 2011; Azam et al. 2014; Wang et al. 2010). In particular, $N$-Acetylglucosamine (GlcNAc) as a unit of chitin has been reported to have a great prospect for the treatment of several diseases, such as osteoarthritis (Talent and Gracy 1996), gastritis, and inflammatory bowel disease (Chen et al. 2011).

Among studies on microbial reclamation of shrimp processing waste, Bacillus cereus has been known as an efficient microorganism for shrimp-waste degradation (Azam et al. 2014; Banik and Prakash 2004; Ghorbel-Bellaaj et al. 2012; Sorokulova et al. 2009; Wang et al. 2009; Wang et al. 2012). The strain B. 
cereus EW5 was reported to produce chitinolytic (Azam et al. 2014), proteolytic, and lipolytic enzymes (Kim et al. 2010). Bioactive chitosaccharides, chitobiose, and GlcNAc were also recovered by SSW biodegradation using the B. cereus EW5 (Azam et al. 2014; Banik and Prakash 2004; Chen et al. 2011; Ghorbel-Bellaaj et al. 2012; Kim et al. 2010; Talent and Gracy 1996; Wang et al. 2009). Since competent production of the chitosaccharides from SSW has not yet reported, it is necessary to study the enhanced SSW biodegradation in a bioreactor level for commercial application.

Fed-batch is a commonly used means for the production of microbial biomass, ethanol, organic acids, antibiotics, vitamins, enzymes, and other compounds in which the culture medium is added continuously or in pulses to reach the maximum volume (Hadiyanto et al. 2013). The advantages of fed-batch over the conventional batch operation include higher biodegradation rate, higher productivity, higher dissolved oxygen (DO) in the medium, and decrease in fermentation time and toxic effect of the medium components (Abou-taleb 2015; Cheng et al. 2009). In the fed-batch operation, the design of the feeding strategy and feed control is of great importance, as both overfeeding and underfeeding of the nutrient affect the cell growth and the formation of desired products (Bretz and Kabasci 2012). The feeding strategies in the fed-batch operation include a constant feeding rate, a pulse feeding rate, and an exponential feeding rate. Since actively growing cells fed at a constant rate in fed-batch operation are overfed at early reaction stages and underfed at later stages, feeding based on the specific growth rate of the main microbe has been known to yield a better bioreaction (Salehmin et al. 2014). In this study, therefore, the production of reducing sugar, antioxidant, and DNA protective compounds was investigated in the fed-batch SSW biodegradation using a pulse feeding strategy for high production. The changes in kinetic parameters and the production of the bioactive compounds were compared with those obtained from the batch biodegradation to demonstrate the advantage of fed-batch biodegradation.

\section{Methods}

\section{Microorganism and culture medium}

The microorganism used in this study was a chitin-degrading strain B. cereus EW5 (GenBank accession no. DQ923487) previously isolated from the earthworm viscera (Azam et al. 2014) and ordinary maintained in the deep freezer at $-70{ }^{\circ} \mathrm{C}$. It has potentially proteolytic and lipolytic activities with fairly good salt endurance. As a competent microorganism, the strain B. cereus EW5 was first cultivated in the liquid nutrient broth after thawing, incubated for $14 \mathrm{~h}$ at $47{ }^{\circ} \mathrm{C}$, and then maintained at $4{ }^{\circ} \mathrm{C}$ for further use.

The culture medium was composed of $(w / v)$ : $1 \%$ shrimp-shell powder (SSP); $0.5 \% \mathrm{NH}_{4} \mathrm{Cl} ; 0.1 \%, \mathrm{~K}_{2} \mathrm{HPO}_{4}$; and $0.05 \% \mathrm{MgSO}_{4} .7 \mathrm{H}_{2} \mathrm{O}(\mathrm{pH} 7.0)$. The SSP was prepared from the shell parts of the frozen whiteleg shrimp (Litopenaeus vannamei) purchased from the local market. The shell parts were initially washed with tap water, boiled for $15 \mathrm{~min}$, and then dried in an oven at $120{ }^{\circ} \mathrm{C}$ for $12 \mathrm{~h}$. The dried shells were ground to powder form, sieved with a particle size of less than $38 \mu \mathrm{m}$, and stored at $4{ }^{\circ} \mathrm{C}$ until used. To activate the biodegradation, the prepared SSP was pretreated: it was sonicated for $1 \mathrm{~h}$, treated with $\mathrm{NaOH}$ at $\mathrm{pH} 12.5 \pm 0.1$ on a hot plate at 80 $\pm 5{ }^{\circ} \mathrm{C}$ with mild stirring for $5 \mathrm{~h}$ for deproteinization, and then treated with $\mathrm{HCl}$ at $\mathrm{pH} 4.0 \pm 0.1$ at room temperature, followed by continuous stirring overnight for demineralization to increase its solubility. The other constituents of the culture medium excluding SSP were separately autoclaved at $121{ }^{\circ} \mathrm{C}$ for $15 \mathrm{~min}$. After then, the other constituents' solution was mixed with the pretreated SSP solution. Finally, the SSP culture medium for biodegradation experiments was prepared after $\mathrm{pH}$ of the mixed solution was adjusted to 7 .

\section{Biodegradation of SSP}

To produce useful compounds from SSP, the biodegradation experiments were carried out in a $5 \mathrm{~L}$ bioreactor (Winpact Bench-Top Fermenter, Major Science, USA) with working volume of $3 \mathrm{~L}$. This bioreactor system was equipped with three six-bladed adjustable Rushton-type impellers, four peristaltic pumps, polarographic DO sensor, $\mathrm{pH}$ electrode, temperature control, inlet air flow meter, baffle, condenser, and real-time recording and control system within the vessel. The stirred reactor was aerated by an air pump (LP-40A, Young Nam Yasunaga Co., Korea). The airflow rate and rotation speed were 2 LPM and $200 \mathrm{rpm}$, respectively. During the biodegradation, DO level was maintained at $50-70 \%$ saturation by adjustment of agitation speed and aeration rate. The inoculum $(10 \%, v / v)$ for the biodegradation was prepared in a $250-\mathrm{mL}$ conical flask containing the $100-\mathrm{mL}$ SSP culture medium. After B. cereus EW5 was seeded, the flask was incubated at $47 \pm 1{ }^{\circ} \mathrm{C}$ and $170 \pm 5 \mathrm{rpm}$ for 1 day to proliferate cells until a log-phase. To prevent severe foaming, $1 \%$ antifoam emulsion was pumped into the reactor. Since evaporative liquid loss was taken place in the reactor due to high reaction temperature and airflow, it was compensated with sterile distilled water (DW). Samples were taken periodically during the biodegradation for analyses of cell density and useful compounds produced from SSP. The culture supernatant was collected by the centrifugation at $4{ }^{\circ} \mathrm{C}$ and $10,000 \mathrm{rpm}$ for $10 \mathrm{~min}$. 
The biodegradation was executed in both batch and fed-batch operations. The bioreactor temperature was $47 \pm 1{ }^{\circ} \mathrm{C}$, $\mathrm{pH}$ was not controlled, and antifoam emulsion was pumped into the bioreactor when foam occurred plentifully. In the batch operation, $2700 \mathrm{~mL}$ of the sterile SSP culture medium was initially filled in the bioreactor vessel. The $\mathrm{pH}$ and $\mathrm{DO}$ probes were calibrated in advance, and all process set points were entered on the control unit installed on the reactor body. The agitation speed was set at $200 \mathrm{rpm}$ with airflow rate of $1.0 \mathrm{vvm}$ for complete mixing. After the parameters were at their set points, $300 \mathrm{~mL}$ of inoculum $(10 \%, v / v)$ was pumped aseptically into the bioreactor vessel using a peristaltic pump. Therefore, the batch biodegradation started with initial working volume of $3 \mathrm{~L}$, and samples were taken periodically for analyses of reaction parameters.

The fed-batch biodegradation started after the characteristic data were obtained from the batch biodegradation. The fed-batch operation was initiated as a batch culture with 1080-mL SSP culture medium and 120-mL $(10 \%, v / v)$ seed culture of B. cereus EW5. According to the growth characteristics of the batch culture, pulse feeding was executed at 14,42 , and $72 \mathrm{~h}$ of biodegradation periods when the cells reached early-, mid-, and late-exponential phases, respectively. The amounts of pulse feeding at 14, 42, and $72 \mathrm{~h}$ were 390,785 , and $625 \mathrm{~mL}$, respectively. The final working volume was $3 \mathrm{~L}$, which was equivalent to the working volume of the batch biodegradation. The SPP culture medium was injected into the bioreactor using a peristaltic pump at a flow rate of $46.80 \mathrm{~mL} / \mathrm{h}$, and the biodegradation lasted for $96 \mathrm{~h}$. All the experiments were carried out in triplicate.

\section{Cell density}

At each sample period, a $10-\mathrm{mL}$ sample was taken from the bioreactor, and $1 \mathrm{~mL}$ was used for the determination of change in cell density during the biodegradation. Against control, the cell density was measured as optical density (OD) using spectrophotometer (Optizen, Mecasys Co., Korea) at $600 \mathrm{~nm}$, and each measurement was carried out in triplicate. The rest of the sample was centrifuged at $4{ }^{\circ} \mathrm{C}$ and $10,000 \mathrm{rpm}$ for $10 \mathrm{~min}$, and then the supernatant was immediately frozen at $-20{ }^{\circ} \mathrm{C}$ for later analyses of reducing sugar, antioxidant activity, and DNA damage inhibition activity.

\section{Measurement of reducing sugar}

A slightly customized method of Imoto and Yagishita (1971) was used to determine the concentration of reducing sugar produced from the SSP. Four milliliters of the color reagent (98\% dinitrosalicylic acid; Sigma-Aldrich, St. Louis, USA) was mixed with $1 \mathrm{~mL}$ of the culture supernatant, followed by incubation in boiling water in a glass tube for $8 \mathrm{~min}$. Then, the absorbance of the mixture was measured using the spectrophotometer at $420 \mathrm{~nm}$ after cooled at room temperature. The concentration of reducing sugar was finally determined by means of the standard curve using GlcNAc (Sigma-Aldrich) as a reference compound.

\section{Antioxidant activities of biodegraded SSP DPPH radical scavenging assay}

To determine the DPPH (2,2-diphenyl-1-picrylhydrazyl) free radical scavenging activity of the culture supernatant, the slightly customized Blois (1958) method was applied. Two milliliters of $0.1 \mathrm{mM}$ DPPH (dissolved in $80 \%$ ethanol) solution was added to $1 \mathrm{~mL}$ of the culture supernatant, and the resultant mixture was placed at room temperature in the dark for $30 \mathrm{~min}$. After then, the mixture solution was measured using the spectrophotometer at $517 \mathrm{~nm}$. The sample blank was prepared by replacing DPPH with $80 \%$ ethanol. DPPH radical scavenging activity was finally obtained from the following calculation:

$$
\text { Scavenging activity }(\%)=\frac{\text { Absorbance of control }- \text { Absorbance of sample }}{\text { Absorbance of control }} \times 100
$$

The control sample was the mixture of $2 \mathrm{~mL}$ of $0.1 \mathrm{mM}$ DPPH and $1 \mathrm{~mL}$ of $80 \%$ ethanol. As a positive control, L-ascorbic acid $(0.1 \mathrm{mM})$ was used under the same measurement conditions. The assay was done in triplicate.

\section{$A B T S$ radical cation decolorization assay}

For ABTS (2, 2' -Azino-bis 3-ethylbenzothiazoline-6-sulfonic acid) radical cation decolorization assay, a slightly customized method of Re et al. (1999) was applied. To prepare the ABTS radical cation (ABTS reagent), $5 \mathrm{~mL}$ of $7 \mathrm{mM}$ ABTS was mixed with $5 \mathrm{~mL}$ of $4.9 \mathrm{mM}$ Potassium persulfate $\left(\mathrm{K}_{2} \mathrm{~S}_{2} \mathrm{O}_{8}\right)$ in DW. The mixture was placed in a dark at room temperature for $16 \mathrm{~h}$. The absorbance of the ABTS reagent was then modulated to $0.720 \pm 0.02$ at $734 \mathrm{~nm}$ with $80 \%$ ethanol. Finally, $1.8 \mathrm{~mL}$ of the ABTS reagents was added to $0.2 \mathrm{~mL}$ of the culture supernatant, followed by measurement of the absorbance at $734 \mathrm{~nm}$. As a positive control, L-ascorbic acid $(0.3 \mathrm{mM})$ was used under the same measurement conditions. The percentage of inhibition was obtained from the following calculation:

$$
\% \text { Inhibition }=\frac{\text { Absorbance of control }- \text { Absorbance of sample }}{\text { Absorbance of control }} \times 100
$$

DW was used as the control, and the sample blank was prepared with $80 \%$ ethanol by replacing the ABTS reagent. The assay was done in triplicate. 


\section{Reducing power assay}

A slightly customized method of Wu et al. (2010) was used for reducing power assay. One milliliter of the culture supernatant was mixed with $1.0 \mathrm{~mL}$ of $0.2 \mathrm{M}$ phosphate buffer $(\mathrm{pH} 6.6)$ and $1.0 \mathrm{~mL}$ of $1 \%$ potassium ferricyanide, followed by incubation at $50{ }^{\circ} \mathrm{C}$ for $20 \mathrm{~min}$. After the incubation, the reaction was stopped by adding $1.0 \mathrm{~mL}$ of $10 \%(w / v)$ trichloroacetic acid, and then the reaction mixture was centrifuged at 3,000 rpm for $10 \mathrm{~min}$. Two milliliters of the centrifuged solution was taken from the upper layer and mixed with $2 \mathrm{~mL}$ of DW and $0.4 \mathrm{~mL}$ of $0.1 \% \mathrm{FeCl}_{3}$, followed by incubation at room temperature for $10 \mathrm{~min}$. After incubation, absorbance of the solutions was measured using the spectrophotometer at $700 \mathrm{~nm}$. The control was prepared with DW by replacing the culture supernatant. The assay was conducted in triplicate.

\section{Determination of DNA damage inhibition}

The protective effect of the biodegraded SSP culture supernatant against hydroxyl radical-induced oxidative DNA was performed according to a slightly customized method of Lee et al. (2002). For the determination of DNA damage inhibition, 2 and $4 \mu \mathrm{L}$ of the 48 -h culture supernatants were exposed to $2 \mu \mathrm{L}$ of $300 \mathrm{ng} / \mu \mathrm{L} \lambda$ DNA (Takara Bio Inc., Japan) with 1/4 concentration of freshly prepared Fenton's reagents (mixture of $20 \mathrm{mM} \mathrm{FeCL}_{3}$, $12.5 \mathrm{mM}$ ascorbic acid and 7.5 $\mathrm{mM}$ hydrogen peroxide). In each determination, two different amounts (2.5 and $5 \mu \mathrm{L}$ ) of Fenton's reagents were used. Positive control was prepared by mixing DW with the $2-\mu \mathrm{L} \lambda$ DNA in the absence of the culture supernatant and Fenton's reagents, while negative control was prepared by mixing $2-\mu \mathrm{L} \lambda$ DNA, 2- $\mu \mathrm{L}$ Fenton's reagents, and $16-\mu \mathrm{L}$ DW excluding the culture supernatant. Final volume of each mixed solution was kept at $20 \mu \mathrm{L}$. Each mixture was then incubated at $37{ }^{\circ} \mathrm{C}$ for $30 \mathrm{~min}$, and the DNA was analyzed on $1.5 \%$ agarose gel, followed by ethidium bromide staining and visualization under UV-transilluminator using Gel Documentation system (Vilber Loumat, France).

\section{Results and discussion}

A batch biodegradation was first executed, and then a fed-batch biodegradation based on the growth characteristics of the batch biodegradation was followed to enhance the production of useful compounds from SSP. The enhancement in the fed-batch operation over the batch operation was evaluated by the comparison between their values of reaction parameters.

\section{Changes in cell density and $\mathrm{pH}$}

A batch biodegradation of SSP using B. cereus EW5 was carried out for $96 \mathrm{~h}$, and changes in cell concentration and $\mathrm{pH}$ are shown in Fig. 1a. The profile of cell density displayed a typical batch growth pattern. For the first $12 \mathrm{~h}$, a lag phase of the cell growth was revealed, followed by early-, mid-, and late-exponential phases. After then, cell growth slowly reached a stationary phase. The highest optical cell density was 2.5 at $96 \mathrm{~h}$. During the biodegradation, the specific growth rate $(\mu)$ gradually slowed down, and those values at early-, mid-, and late-exponential phases were approximately $0.04,0.03$, and $0.02 \mathrm{~h}^{-1}$, respectively. This tendency in the growth rate was also shown in the previous study of SSP biodegradation (Azam et al. 2014). Meanwhile, $\mathrm{pH}$ dropped to 6.43 for the first $12 \mathrm{~h}$, and thereafter, it started to increase to 7.09 for the next $12 \mathrm{~h}$ of biodegradation (Fig. 1b). The drop in $\mathrm{pH}$ occurred when SSP was deproteinized and demineralized by B. cereus EW5 (Rao et al. 2000), and accumulation of chitosaccharides containing an amino group caused an increase in $\mathrm{pH}$ (Halder et al. 2013). Similar findings were found in other studies of shellfish-waste biodegradations (Rajdeep and Krishna 2012; Wang et al. 2009). After 24 h, the $\mathrm{pH}$ decreased gradually and reached at the lowest value of 4.57 at $96 \mathrm{~h}$. This result was supported by the study of Ghorbel-Bellaaj et al. (2011) in which pH dropped from 7.0 to 4.4 over 7 days of SSP fermentation using Pseudomonas aeruginosa. In that study, the demineralization rate was the maximum (92\%) when the $\mathrm{pH}$ reached at 4.4. Similar result was also found from the chitin fermentation using Chitinbacter tainanesis (Chen et al. 2010). In this case, $\mathrm{pH}$ decreased gradually from 7.4 to 5.3 for $14 \mathrm{~h}$.

After the batch biodegradation, a fed-batch biodegradation was executed using the pulse feeding strategy. The amounts of feeding substrates were 390, 785, and $625 \mathrm{~mL}$ at 14,42 , and $72 \mathrm{~h}$, respectively, to adjust the dilution rate to $\mu$ at each growth phase characterized from the batch biodegradation. The change in the cell density in the fed-batch operation is shown in Fig. 1a. During the first batch-type operation with working volume of $1.2 \mathrm{~L}$ for $14 \mathrm{~h}$, a relatively high value of optical cell density was displayed, compared with that of the batch operation with working volume of $3 \mathrm{~L}$. This was probably because the environmental conditions of aeration and mixing were more favorable to a smaller quantity of working volume (Gwon and Kim 2012). Cell proliferation increased after the first pulse feeding for $14 \mathrm{~h}$, and this trend was more intense after the second and third pulse feedings. The optical cell density (4.76 at $\left.\mathrm{OD}_{600}\right)$ in the fed-batch biodegradation at $96 \mathrm{~h}$ was approximately 1.9 times as much as that (2.5) of the batch biodegradation. This result indicates that the fed-batch operation was more favorable for cell proliferation than the batch operation. It was because the pulse feeding was based on $\mu$ of $B$. cereus EW5, providing a better environment for cell growth (Abou-taleb 2015). Meanwhile, the change in $\mathrm{pH}$ showed a little different pattern in the fed-batch biodegradation (Fig. 1b). For the first $24 \mathrm{~h}$, the pattern of $\mathrm{pH}$ was 


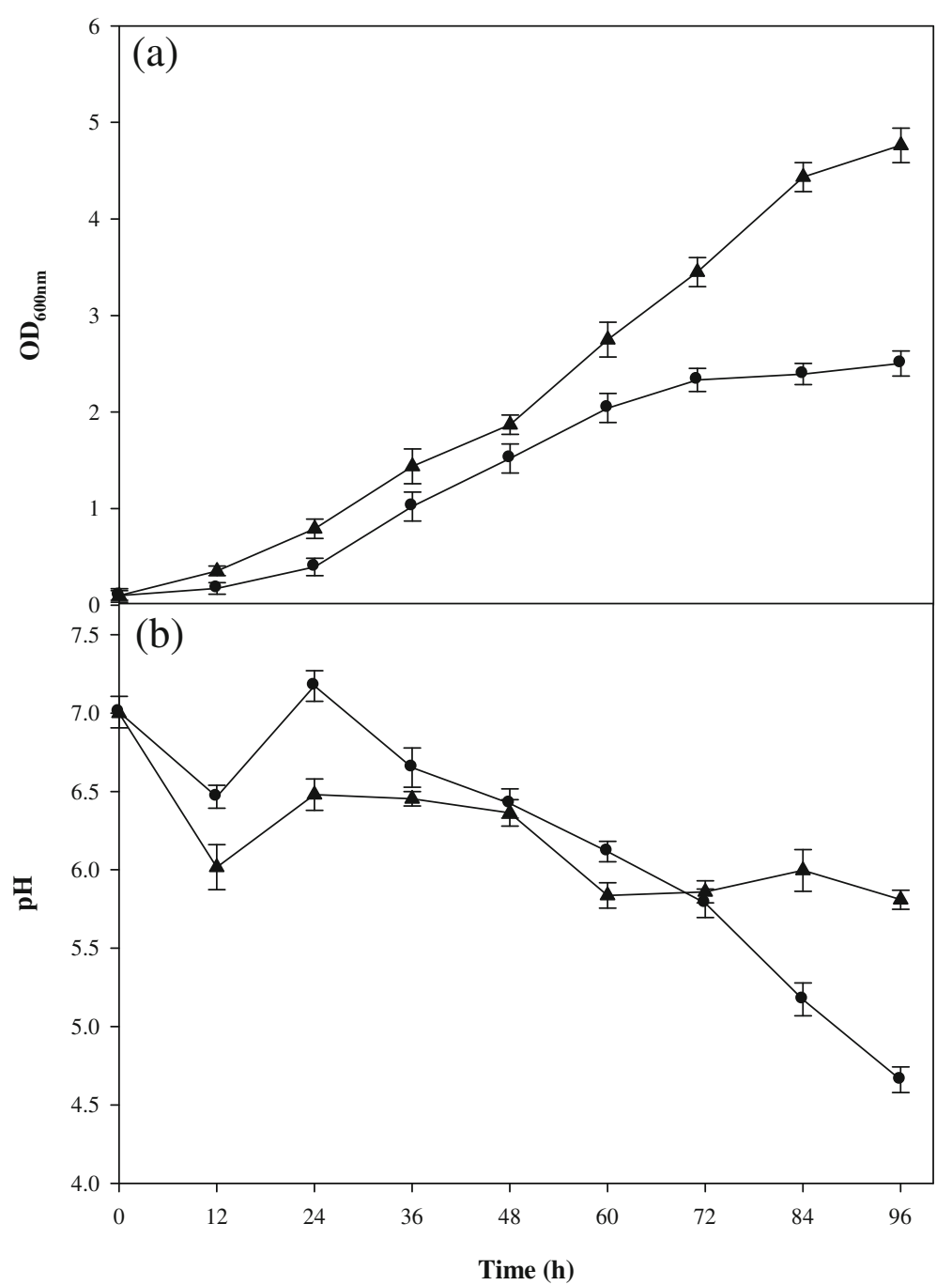

Fig. 1 Changes in the optical cell density (a) and pH (b) during the batch biodegradation (circle) and the fed-batch (tringle) biodegradation of $1 \%$ SSP by B. cereus EW5. All data correspond to the mean \pm SD $(n=3)$ of triplicate determination

similar to that of the batch biodegradation. After then, $\mathrm{pH}$ slightly fluctuated between 5.74 and 6.50 . In the batch biodegradation, on the other hand, $\mathrm{pH}$ gradually dropped to 4.57 until the end. Therefore, additional substrate feeding in the fed-batch operation might contribute better cell growth and consequently lead the production of various metabolites (Abou-taleb 2015). It was also reported that change in alkalinity was caused due to breakage of peptide linkages of chitin by proteolysis (Bajaj et al. 2016), and high demineralization rate was found at $\mathrm{pH} 5.86$ during the batch degradation of chitin (Ghorbel-Bellaaj et al. 2011). GlcNAc was reported to result from the chitin degradation optimally at $\mathrm{pH} 5.3$ (Chen et al. 2010). From all the above information, it was concluded that a different $\mathrm{pH}$ pattern shown in the fed-batch biodegradation was due to the enhancement in cell density with higher production of metabolites.

\section{Production of reducing sugar}

During the biodegradation of SSP, reducing sugar as one of useful compounds was produced by B. cereus EW5. The reducing sugar was produced from the beginning of the batch biodegradation, and its concentration increased until $60 \mathrm{~h}$, with the maximum value of $0.265 \mathrm{mg} / \mathrm{mL}$ (Fig. 2). After then, it decreased slightly to $0.222 \mathrm{mg} / \mathrm{mL}$ at $96 \mathrm{~h}$. This trend could be generally found in the biodegradation using polymer substrates (Azam et al. 2014). Up to the middle of exponential growth phase, the strain EW5 continuously produced the reducing sugar by its extracellular chitinolytic enzyme. Meanwhile, decrease in the reducing sugar concentration at a later biodegradation period was probably because the strain EW5 utilized the reducing sugar as an easier uptake substrate, instead of SSP. In the previous study (Azam et al. 2014), $0.24 \mathrm{mg} / \mathrm{mL}$ of reducing sugar 


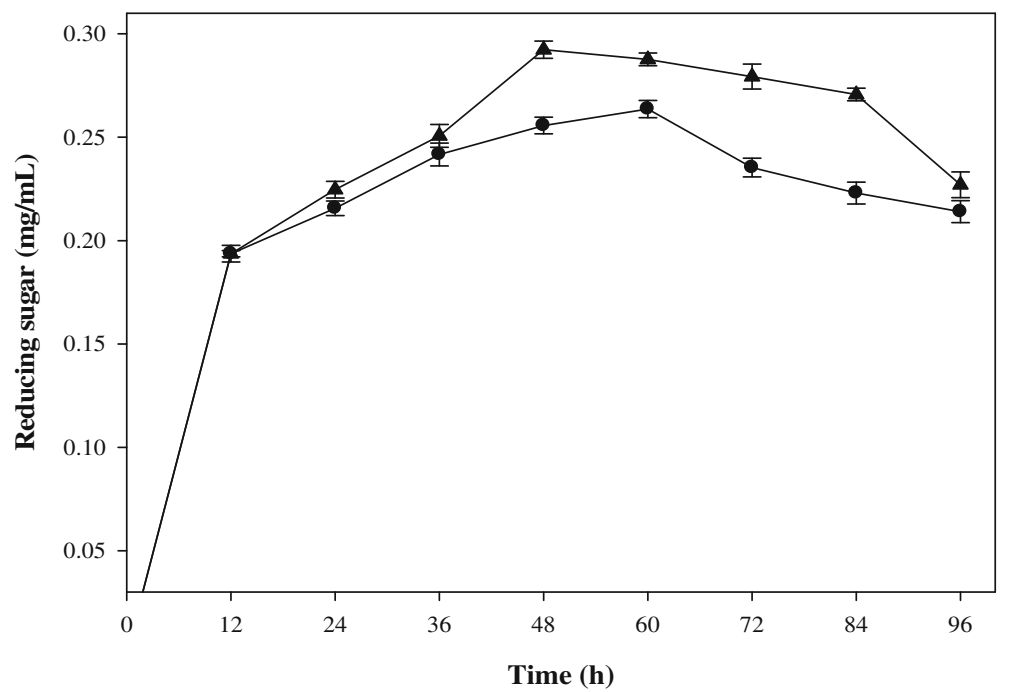

Fig. 2 Production of reducing sugar during the batch biodegradation (circle) and the fed-batch (triangle) biodegradation of $1 \%$ SSP by B. cereus EW5. All data correspond to the mean \pm SD $(n=3)$ of triplicate determination

was produced from SSP after 4 days of incubation in a shake-flask level. Therefore, batch culture in a bioreactor level clearly enhanced the production of reducing sugar and simultaneously shortened the biodegradation time.

In the fed-batch biodegradation prior to the pulse feeding, the pattern of reducing-sugar production followed that of the batch biodegradation (Fig. 2). After the pulse feeding, the production rate of reducing sugar in the fed-batch biodegradation exceeded that of the batch biodegradation. The maximum value of $0.297 \mathrm{mg} / \mathrm{mL}$ was achieved at $48 \mathrm{~h}$, and it maintained more or less up to $84 \mathrm{~h}$. This value was approximately $12.1 \%$ higher than that of the batch biodegradation with shorter biodegradation time. As a result, the substrate feeding adjusted to $\mu$ of the strain EW5 could provide a better environment for production of reducing sugar. The concentration of reducing sugar also decreased in the later fed-batch biodegradation, as shown in the batch biodegradation.

\section{Antioxidant activities of the biodegraded compounds $D P P H$ radical scavenging activity}

As a bioactive compound, an antioxidant has been known to be produced from the SSP biodegradation (Azam et al. 2014). For this reason, three different types of antioxidant activities were measured for the biodegraded products produced from the batch and fed-batch biodegradations. First, DPPH radical was applied to measure the free-radical scavenging capacity of the culture supernatant. In this measurement, reduction in absorbance occurred by scavenging the free radicals when DPPH radicals encountered a proton-donating substance (Bersuder et al. 1998). As shown in Fig. 3, DPPH radical scavenging activity in the batch operation increased as SSP was biodegraded up to $60 \mathrm{~h}$ with a value of $89.33 \%$, and then it decreased gradually to $66.57 \%$ at the end. The maximum activity was superior to the positive control of $0.1 \mathrm{mM} \mathrm{L-Ascorbic} \mathrm{acid} \mathrm{(81.35 \% ).}$ The DPPH radical scavenging activities reported in the previous studies ranged over a wide variety of values: $56 \%$ DPPH radical scavenging activity from SSP fermentation using B. cereus (Wang et al. 2009); 64.86 and 79.84\% activities from cooked and raw shells of shrimp (Litopenaeus schmitti), respectively (Lira et al. 2017); 68.5-83.4\% activities during 8 days of biodegradation (Azam et al. 2014); $82 \%$ activity from shrimp waste by treatment with crude protease isolated from Bacillus cereus SV1 (Manni et al. 2010); $82.5 \%$ activity after $64 \mathrm{~h}$ of SSP biodegradation using Aeromonas hydrophila SBK1 (Halder et al. 2013); and $90 \%$ maximum activity after 3 days of SSP fermentation using Pseudomonas aeruginosa (Ghorbel-Bellaaj et al. 2011). Although the DPPH radical scavenging activity could become different with the reaction conditions, a relatively high activity was obtained through this study.

The DPPH radical scavenging activity was enhanced by the fed-batch operation. The maximum value of $92.35 \%$ was determined at $48 \mathrm{~h}$, and the activity remained more or less until $84 \mathrm{~h}$. Thereafter, it decreased to $75.63 \%$ at the end. The DPPH radical scavenging activity was overall enhanced, the maximum activity was achieved in a shorter biodegradation time, and the activity was maintained for a longer time, compared with the result of the batch operation. The enhancement in the DPPH radical scavenging activity could result from the maintenance of active biodegradation using the pulse feeding adjusted to $\mu$ of $B$. cereus EW5. Protein-astaxanthin complexes of shrimp waste were reported to produce a complex mixture of bioactive compounds (free amino acids, peptides, carotenoids, etc.) by the 


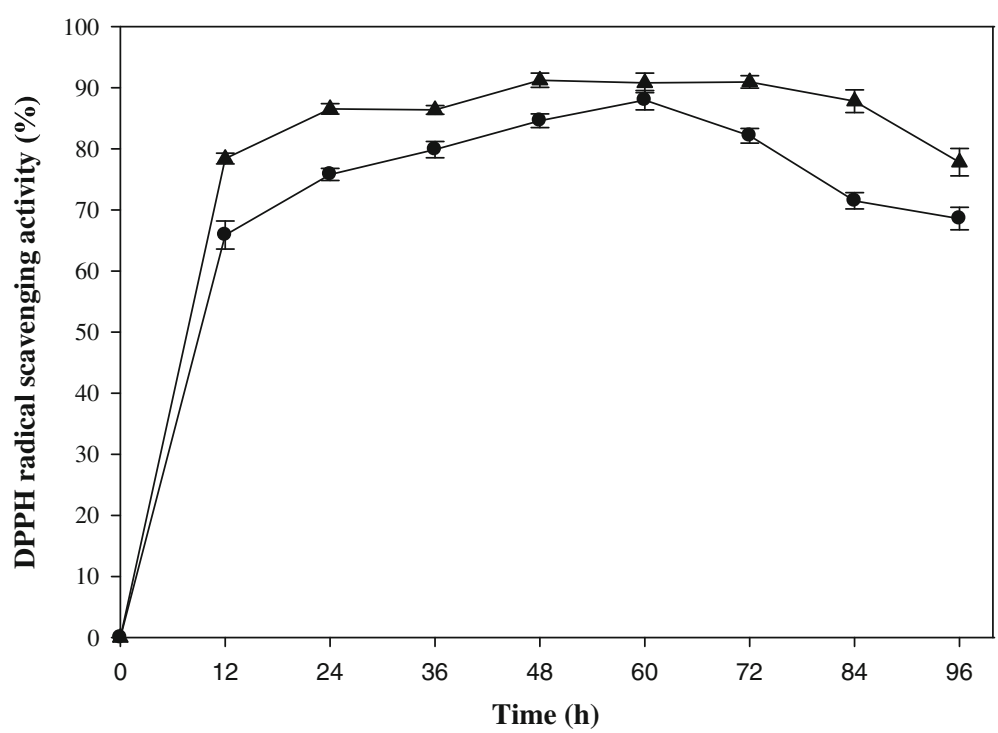

Fig. 3 DPPH free radical scavenging activity of 1-mL culture supernatant during the batch biodegradation (circle) and the fed-batch biodegradation (triangle) of $1 \%$ SSP by B. cereus EW5. All data correspond to the mean \pm SD $(n=3)$ of triplicate determination

bacterial enzyme hydrolysis (Manni et al. 2010). Consequently, the fed-batch culture supernatant could contain more oxidant compounds that acted as electron donors, which converted the free radical to more stable products and terminated the radical chain reaction.

\section{$A B T S$ radical scavenging activity}

The ABTS radical cation decolorization assay was applied to measure the antioxidant activity of the culture supernatant. It is often used to evaluate the antioxidant activity of both lipophilic and hydrophilic antioxidant (Bersuder et al. 1998). The ABTS radical scavenging activity of the batch culture supernatant ranged from 71.42 to $93.33 \%$ during $96 \mathrm{~h}$ of biodegradation (Fig. 4). These activities were superior to that (73.2\%) of $0.3-\mathrm{mM}$ ascorbic acid as a positive control. In the same manner, Sachindra and Bhaskar (2008) reported high radical scavenging activity of $94.82 \%$ from the fermentation of SSP, and Azam et al. (2014) reported high radical scavenging activity of $93.4-99.6 \%$ during the biodegradation

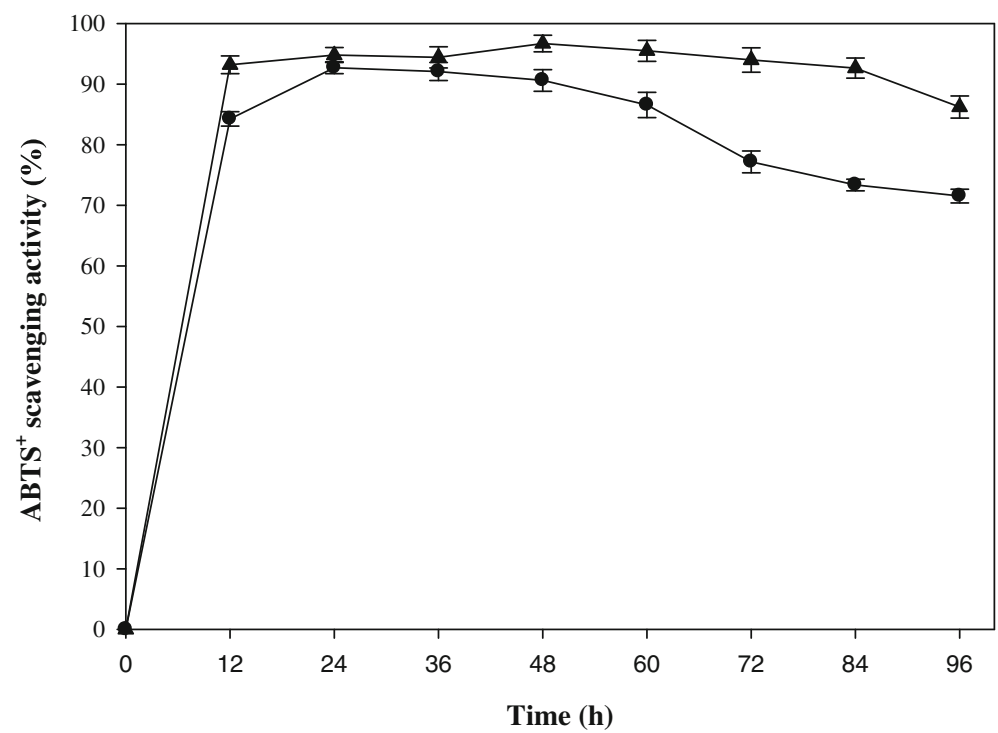

Fig. 4 ABTS radical scavenging activity of $0.2-\mathrm{mL}$ culture supernatant during the batch biodegradation (circle) and the fed-batch biodegradation (triangle) of $1 \%$ SSP by B. cereus EW5. All data correspond to the mean \pm SD $(n=3)$ of triplicate determination 
of SSP. On the contrary, Walke et al. (2014) reported $24 \%$ ABTS scavenging activity from shrimp shell against a positive control $(0.05 \mathrm{mg} / \mathrm{mL}$ butylated hydroxyanisole), Sujeetha et al. (2015) reported $41 \%$ activity from mud crab (Scylla serrata) extracts, and Lira et al. (2017) reported 43.86 and $45.23 \%$ activities for cooked and raw shells of shrimp (Litopenaeus schmitti), respectively.

In this study, the ABTS radical scavenging activity was enhanced by the fed-batch operation (Fig. 4). The ABTS radical scavenging activity ranged $85.70-98.16 \%$ during 96-h fed-batch operation, and the highest activity was achieved after $48 \mathrm{~h}$. In the fed-batch operation, there was no big drop in the ABTS radical scavenging activity until the end of biodegradation, which was not displayed in the batch operation. This indicates that the pulse feeding provided a better environment for the production of antioxidant compounds in the fed-batch operation. High ABTS radical scavenging activity was known to be caused mostly by the production of GlcNAc and chitobiose from SSP (Azam et al. 2014). This high ABTS scavenging activity was also reported in the study of SSP fermentation by Sachindra and Bhaskar (2008).

\section{Reducing power}

The reducing power assay is often used to appraise the ability of an antioxidant to donate electron or hydrogen (Gao et al. 2012). It was known that there was a direct correlation between antioxidant activity and reducing power of certain bioactive compounds (Bahri-Sahloul et al. 2014). Accordingly, the action of antioxidant compounds resulted in the neutralization of free radicals, converting them into more stable non-reactive species and thus terminating the free radical-initiated chain reactions (Bersuder et al. 1998). In this study, the reducing power of the batch culture supernatant showed a linear increase with time (Fig. 5). The highest value (1.43) of reducing power was recorded at $96 \mathrm{~h}$ against the control (0.025). As reported in other studies (Ghorbel-Bellaaj et al. 2012; Sachindra and Bhaskar 2008; Wang et al. 2009), a positive correlation between reducing power and antioxidant activity based on the radical scavenging activity was also found in this study. The reducing power reported in previous studies of SSP were in a wide range of values: Azam et al. (2014) reported a reducing power of 0.34 after 5 days of incubation in a flask level, whereas Maruthiah (2017) reported 1.32 as the reducing power of SSP hydrolysate. Furthermore, a reducing power of 1.7 was reported after 1 day of SSP fermentation using P. aeruginosa (Ghorbel-Bellaaj et al. 2011), and a reducing power of 1.55 was reported for hydrolysate of SSP achieved by Bacillus pumilus A1 (Ghorbel-Bellaaj et al. 2012). Although the production of reducing power compounds from SSP could vary under different culture conditions, a relatively high reducing power was obtained through this study.

In the fed-batch operation, the reducing power of the culture supernatant also increased linearly with time (Fig. 5). The highest value of reducing power was 1.55 at $96 \mathrm{~h}$, which was enhanced by $8 \%$ in comparison with that of batch operation. It was reported that antioxidant activity was closely related to the concentrations of bioactive compounds, such as phenolics, chitooligosaccharides, oligopeptides, peptides, and free amino acids, and they were most likely produced during the fermentation

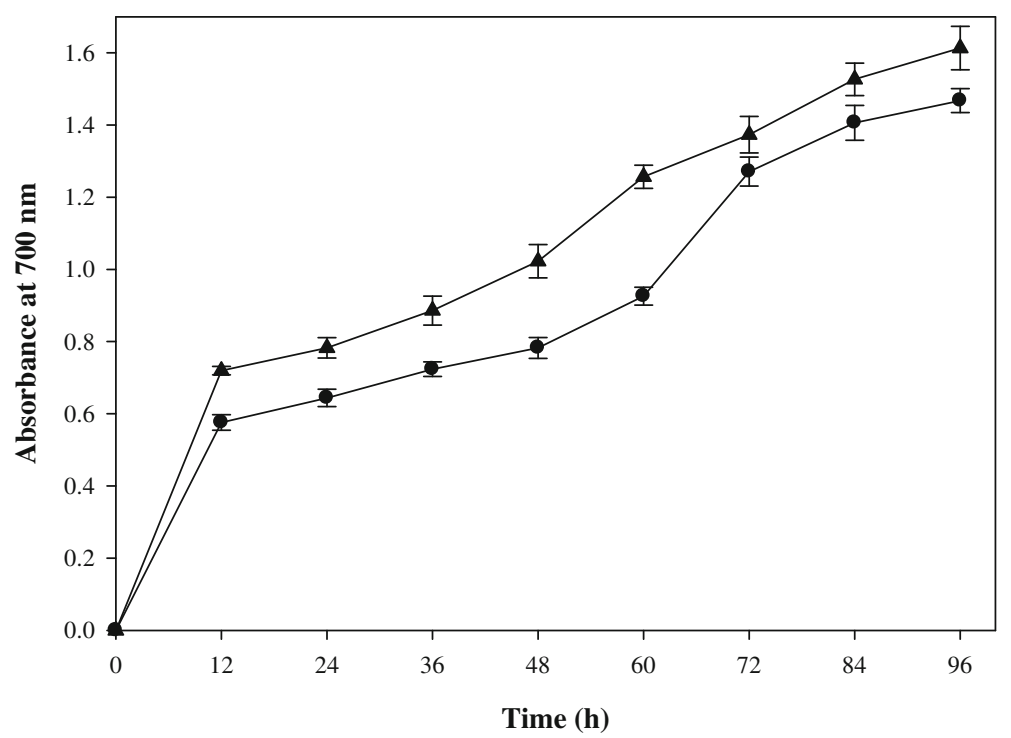

Fig. 5 Reducing power of the culture supernatant during the batch biodegradation (circle) and the fed-batch biodegradation (triangle) of 1\% SSP by $B$. cereus EW5. All data correspond to the mean $\pm \mathrm{SD}(n=3)$ of triplicate determination 
of shrimp waste (Ghorbel-Bellaaj et al. 2012; Sachindra and Bhaskar 2008; Wang et al. 2009). As a result, the enhancement in reducing power in the fed-batch operation could result from high production of antioxidant compounds by the pulse feeding adjusted to $\mu$ of the strain EW5.

\section{DNA damage inhibition activity}

Free hydroxyl radicals were known to induce some damage to the DNA, leading to mutation (Saenjum et al. 2010) or further to cell death (Kim et al. 2012). For this reason, natural antioxidant compounds are concerned about their protective ability of cellular components. To evaluate DNA damage inhibition activity of the 48-h culture supernatant, hydroxyl radicals were exposed to $\lambda$ DNA either in the presence or in the absence of the culture supernatant. As shown in Fig. 6, DNA damage inhibition activity did not appear in the absence of the culture supernatant. When $2 \mu \mathrm{L}$ of the 48 -h culture supernatant was applied to this assay, $\lambda$ DNA treated with $2.5 \mu \mathrm{L}$ of Fenton's reagents (containing hydroxyl radicals) displayed a clear band exclusively in the presence of the fed-batch culture supernatant (lane 5 in Fig. 6a). Compounds produced from SSP were reported to have DNA protection activity against damage by hydroxyl radicals and recommended for potential use in gene therapy: astaxanthin (Sila et al. 2013) and chitosaccharidies (Halder et al. 2014) from the treatment of protease and chitinase, respectively. In this study, however,
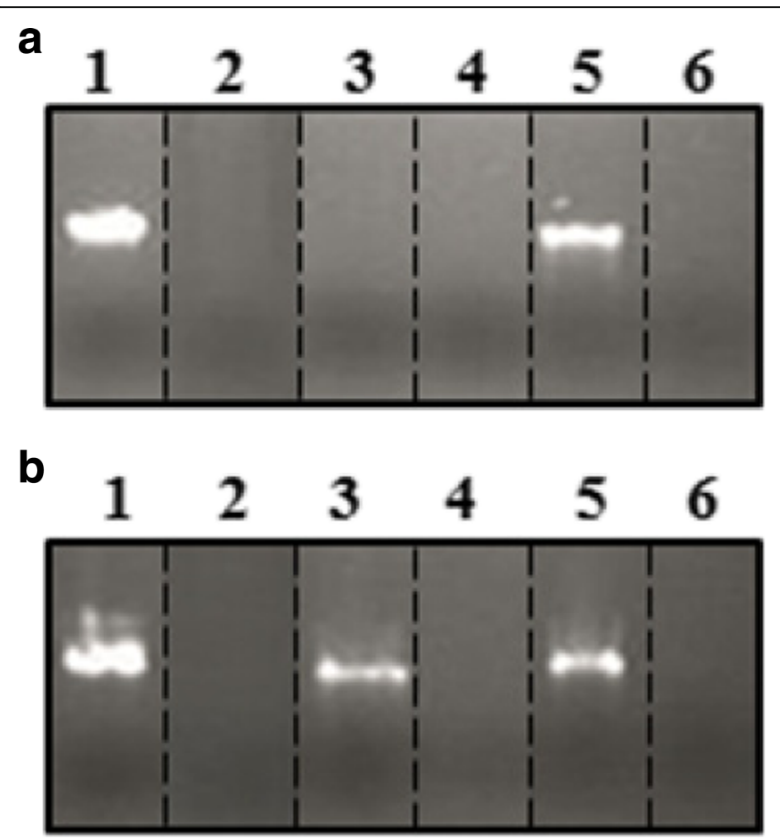

Fig. 6 DNA damage inhibition activities at $2 \mu \mathrm{L}$ (a) and $4 \mu \mathrm{L}$ (b) of the 48-h culture supernatants. Lane 1: positive control; lane 2: negative control; lane 3-4: batch culture supernatants with 2.5 and $5 \mu \mathrm{L}$ of Fenton's reagents, respectively; and lane 5-6: fed-batch supernatants with 2.5 and $5 \mu \mathrm{L}$ of Fenton's reagents, respectively the DNA damage inhibition activity did not appear in the presence of either the batch culture supernatant or a higher free-radical concentration at $5 \mu \mathrm{L}$ of Fenton's reagents. When $4 \mu \mathrm{L}$ (as a double dose) of the 48 -h culture supernatant was exposed to $\lambda$ DNA, the DNA damage inhibition activity of the batch culture supernatant could be clearly visible on 1.5\% agarose gel (lane 3 in Fig. 6b), which was not shown in $2 \mu \mathrm{L}$ of the batch culture supernatant. However, any DNA damage inhibition activity was still not displayed in the present of $5 \mu \mathrm{L}$ of Fenton's reagents, even if the dose of the culture supernatant was doubled. From the above results, it was concluded that the DNA damage inhibition activity of the fed-batch culture supernatant was superior to that of the batch culture supernatant. This was because relatively high production of DNA damage inhibitory compounds was obtained from the fed-batch operation under a better environment for SSP biodegradation (Abou-taleb 2015).

\section{Conclusions}

For commercial-scale production, production of useful compounds from SSP in a reactor level was investigated. A fed-batch biodegradation using a pulse feeding strategy demonstrated an enhancement in reducing sugar concentration, antioxidant activities, and DNA damage inhibition activity, compared with those obtained from the batch biodegradation. This enhancement was accompanied by high cell density and shortened biodegradation period. As a result, it could not only increase the reutilization value of SSW, but also provide a solution for environmental pollution problem. To our knowledge, this is the first scientific report about the enhanced production of useful compounds from SSP through the fed-batch operation.

\section{Abbreviations}

A: Absorbance; ABTS: 2, 2'-Azino-bis 3-ethylbenzothiazoline-6-sulfonic acid; DNA: Deoxyribonucleic acid; DO: Dissolved oxygen; DPPH: 2, 2-Diphenyl-1picrylhydrazyl; DW: Distilled water; GlcNAc: N-Acetylglucosamine; SSP: Shrimp-shell powder; SSW: Shrimp-shell waste

\section{Acknowledgements}

Harun Rashid expresses his gratitude for the kind support of KOICA (Korea International Cooperation Agency)-PKNU (Pukyong National University) International Graduate Program of Fisheries Science (IGPFS) scholarship.

\section{Availability of data and materials}

All datasets in this study are available from the corresponding author on reasonable request.

\section{Authors' contributions}

JKK designed this study, interpreted the results, and edited the manuscript. HAR conducted the experiments and wrote the draft of the manuscript. HYJ initiated the experimental technique and plotted the data. All authors read and approved the final article.

Ethics approval and consent to participate Not applicable. 


\section{Consent for publication}

Not applicable.

\section{Competing interests}

The authors declare that they have no competing interests.

\section{Publisher's Note}

Springer Nature remains neutral with regard to jurisdictional claims in published maps and institutional affiliations.

\section{Received: 12 December 2017 Accepted: 27 August 2018}

\section{Published online: 23 October 2018}

\section{References}

Abou-taleb KA. Enhancing production of amino acids from Bacillus spp. using batch and fed-batch fermentation strategies. Br Microbiol Res J. 2015;5:257-72.

Annamalai N, Rajeswari MV, Vijayalakshmi S, Balasubramanian T. Purification and characterization of chitinase from Alcaligenes faecalis AU02 by utilizing marine wastes and its antioxidant activity. Ann Microbiol. 2011;61:801-7.

Azam MS, Kim EJ, Yang HS, Kim JK. High antioxidant and DNA protection activities of $\mathrm{N}$-acetylglucosamine (GlcNAc) and chitobiose produced by exolytic chitinase from Bacillus cereus EW5. SpringerPlus. 2014;3:354-64.

Bahri-Sahloul R, Fredj RB, Boughalleb N, Shriaa J, Saguem S, Hilbert J, Trotin F, Ammar S, Bouzid S, Harzallah-Skhiri F. Phenolic composition and antioxidant and antimicrobial activities of extracts obtained from Crataegus azarolus $\mathrm{L}$. var. arona (Wild) Batt. Ovaries Calli J Bot. 2014;2014:1-11.

Bajaj M, Freiberg A, Winter J, Xu Y, Gallert C. Pilot-scale chitin extraction from shrimp shell waste by deproteination and decalcification with bacterial enrichment cultures. Biomass Bioenergy. 2016;91:37-47.

Banik RM, Prakash M. Laundry detergent compatibility of the alkaline protease from Bacillus cereus. Microbiol Res. 2004;159:135-40.

Bersuder P, Hole M, Smith G. Antioxidant from a heated histidine-glucose model system. I: investigation of the antioxidant role of histidine and isolation of antioxidants by high performance liquid chromatography. J Am Oil Chem Soc. 1998;75:181-7.

Blois MS. Antioxidant determinations by the use of a stable free radical. Nature. 1958;181:1199-200

Bretz K, Kabasci S. Feed-control development for succinic acid production with Anaerobiospirillum succiniciproducens. Biotechnol Bioeng. 2012;109:1187-92.

Chen JK, Shen CR, Liu CL. N-acetylglucosamine: production and applications. Mar Drugs. 2010;8:2493-516.

Chen JK, Shen CR, Yeh CH, Fang BS, Huang T, Liu CL. N-acetyleglucosamine obtained from chitin by chitin degrading factors in Chitinbacter tainanesis. Int J Mol Sci. 2011:12:1187-95.

Cheng NG, Hasan M, Kumoro AC, Ling CF, Tham M. Production of ethanol by fed-batch fermentation. Pertanika J Sci Technol. 2009:17:399-408.

Gao Y, Zhao J, Zu Y, Fu Y, Liang L, Lou M, Wang W, Efferth T. Antioxidant properties, superoxide dismutase and glutathione reductase activities in HepG2 cells with a fungal endophyte producing apigenin from pigeon pea [ Cajanus cajan (L.) Millsp.]. Food Res Int. 2012:49:147-52.

Ghorbel-Bellaaj O, Hmidet N, Jellouli K, Younes I, Maalej H, Hachicha R, Nasri M. Shrimp waste fermentation with Pseudomonas aeruginosa A2: optimization of chitin extraction conditions through Plackett-Burman and response surface methodology approaches. Int J Biol Macromol. 2011;48:596-602.

Ghorbel-Bellaaj O, Jridi M, Khaled HB, Jellouli K, Nasri M. Bioconversion of shrimp shell waste for the production of antioxidant and chitosan used as fruit juice clafier. Int J Food Sci Tech. 2012;47:1835-41.

Gwon BK, Kim JK. Feasibility study on production of liquid fertilizer in a $1 \mathrm{~m}^{3}$ reactor using fishmeal wastewater for commercialization. Environ Eng Res. 2012;17:3-8.

Hadiyanto $H$, Ariyanti D, Aini AP, Pinundi DS. Batch and fed-batch fermentation system on ethanol production from whey using Kluyveromyces marxianus. Int J Renew Energy Dev. 2013;2:127-31.

Halder SK, Jana A, Das A, Paul T, Mohapatra PKD, Pati BR, Mondal KC. Appraisal of antioxidant, anti-hemolytic and DNA shielding potentials of chitosaccharides produced innovatively from shrimp shell by sequential treatment with immobilized enzymes. Food Chem. 2014;158:325-34.

Halder SK, Maity C, Jana A, Das A, Paul T, Mohapatra PKD, Pati BR, Mondal KC. Proficient biodegradation of shrimp shell waste by Aeromonas hydrophila SBK1 for the concomitant production of antifungal chitinase and antioxidant chitosaccharides. Int Biodeterior Biodegrad. 2013;79:88-97.
Imoto T, Yagishita K. A simple activity measurement of lysozome. Agric Biol Chem. 1971:35:1154-6.

Kim EY, Kim YR, Nam TJ, Kong IS. Antioxidant and DNA protection activities of a glycoprotein isolated from a seaweed, Saccharina japonica. Int J Food Sci Tech. 2012;47:1020-7.

Kim JK, Dao VT, Kong IS, Lee HH. Identification and characterization of microorganisms from earthworm viscera for the conversion of fish wastes into liquid fertilizer. Bioresour Technol. 2010;101:5131-6.

Lee JC, Kim HR, Kim I, Jang YS. Antioxidant property of an ethanol extract of the stem of Opuntiaficus-indica var. saboten. J Agric Food Chem. 2002; 50:6940-496.

Liang TW, Chen YJ, Yen YH, Wang SL. The antitumor activity of the hydrolysates of chitinous materials hydrolyzed by crude enzyme from Bacillus amyloliquefaciens V656. Process Biochem. 2007;42:527-34.

Lira GM, Lopez AMQ, Firmino GO, Santos SD, Bezerra RS. Total carotenoids and antioxidant activity of fillets and shells (in natura or cooked) of "Vila Franca" shrimp (Litopenaeus schmitti) in different intervals of storage under freezing. Cienc Agrotec. 2017;41:94-103.

Manni L, Bellaaj OG, Jellouli K, Younes I, Nasri M. Extraction and characterization of chitin, chitosan, and protein hydrolysates prepared from shrimp waste by treatment with crude protease from Bacillus cereus SV1. Appl Biochem Biotechnol. 2010;162:345-57.

Maruthiah T. Characterization of haloalkalophilic organic solvent tolerant protease for chitin extraction from shrimp shell waste. Int J Biol Macromol. 2017;97:552-60.

Rajdeep K, Krishna P. Biodegradation of tiger prawn shell by lactic acid fermentation. J Environ Res Develop. 2012;7:936-45.

Rao MS, Munoz J, Slevens WF. Critical factors in chitin production by fermentation of shrimp biowaste. Appl Microbiol Biotechnol. 2000;54: 808-13.

Re R, Pellegrini N, Proteggente A, Pannala A, Yang M, Riceevans C. Antioxidant activity applying an improved ABTS radical cation decolorization assay. Free Radic Biol Med. 1999;26:1231-7.

Sachindra NM, Bhaskar N. In vitro antioxidant activity of liquor from fermented shrimp biowaste. Bioresour Technol. 2008;99:9013-6.

Saenjum C, Chaiyavat C, Kadchumsang S, Chansakaow S, Suttajit M. Antioxidant activity and protective effects on DNA damage of Caesalpinia sappan L. extract. J Med Plants Res. 2010;4:1594-600.

Salehmin MNI, Annuar MSM, Chisti Y. High cell density fed-batch fermentation for the production of a microbial lipase. Biochem Eng J. 2014;85:8-14.

Sila A, Ayed-Ajmi Y, Sayari N, Nasri M, Martinez-Alvarez O, Bougatef A. Antioxidant and anti-proliferative activities of astaxanthin extracted from the shrimp waste of deep water pink shrimp (Parapenaeus longirostris). Nat Prod J. 2013; 3:82-9.

Sorokulova I, Krumnow A, Globa L, Vodyanoy V. Efficient decomposition of shrimp shell waste using Bacillus cereus and Exiguobacterium acetylicum. J Ind Microbiol Biotechnol. 2009;36:1123-6.

Sujeetha M, Sharmila S, Jayanthi J, Ragunathan MG. Antioxidant property of some extracts derived from the mud crab Scylla serrata. Int J Phytopharmacol. 2015;6:111-3.

Suresh PV. Biodegradation of shrimp processing bio-waste and concomitant production of chitinase enzyme and $\mathrm{N}$-acetyle-D-glucosamine by marine bacteria: production and process optimization. World J Microbiol Biotechnol. 2012;28:2945-62

Talent JM, Gracy RW. Pilot study of oral polymetric N-acetyl-D-glucosamine as a potential treatment for patients with osteoarthritis. Clin Ther. 1996;18:1184-90.

Tsai GJ, Wu ZY, Su WH. Antibacterial activity of a chitooligosaccharide mixture prepared by cellulase digestion of shrimp chitosan and its application to milk preservation. J Food Prot. 2000;63:747-52.

Walke S, Srivastava G, Nikalje M, Doshi J, Kumar R, Ravetkar S, Doshi P. Physicochemical and functional characterization of chitosan prepared from shrimp shells and investigation of its antibacterial, antioxidant and tetanus toxoid entrapment efficiency. Int J Pharm Sci Rev Res. 2014;26:215-25.

Wang SL, Chen SJ, Wang CL. Purification and characterization of chitinases and chitosanases from a new species strain Pseudomonas sp. TKU015 using shrimp shells as a substrate. Carbohydr Res. 2008a;343:1171-9.

Wang SL, Chen TR, Liang TW, Wu PC. Conversion and degradation of shellfish wastes by Bacillus cereus TKU018 fermentation for the production of chitosanases and bioactive materials. Biochem Eng J. 2009:48:111-7.

Wang SL, Li JY, Liang TW, Hsieh JL, Tseng WN. Conversion of shrimp shell by using Serratia sp. TKU017 fermentation for the production of enzymes and antioxidants. J Microbiol Biotechnol. 2010;20:117-26. 
Wang SL, Lin HT, Liang TW, Chen YJ, Yen YH, Guo SP. Reclamation of chitinous materials by bromelain for the preparation of antitumor and antifungal materials. Bioresour Technol. 2008b;99:4386-93.

Wang SL, Liu CP, Liang TW. Fermented and enzymatic production of chitin chitosan oligosaccharides by extracellular chitinases from Bacillus cereus TKU027. Carbohydr Polym. 2012;90:1305-13.

Wang SL, Yeh PY. Purification and characterization of a chitosanase from a nattokinase producing strain Bacillus subtilis TKU007using shrimp powder as a medium. Process Biochem. 2008;43:132-8.

Wu N, Zu YG, Fu YJ, Kong Y, Zhao JT, Li XJ, Wink M, Efferth T. Antioxidant activities and xanthine oxidase inhibitory effects of extracts and main polyphenolic compounds obtained from Geranium sibiricum L. J Agric Food Chem. 2010;58:4737-43.

Ready to submit your research? Choose BMC and benefit from:

- fast, convenient online submission

- thorough peer review by experienced researchers in your field

- rapid publication on acceptance

- support for research data, including large and complex data types

- gold Open Access which fosters wider collaboration and increased citations

- maximum visibility for your research: over $100 \mathrm{M}$ website views per year

At BMC, research is always in progress.

Learn more biomedcentral.com/submissions 